\title{
Post Mortem Artefacts that Mimic Deliberate Physical Violence and Ante Mortem Lesions - Revisited
}

\author{
J. Warushahennadi', P. R. Ruwanpura ${ }^{2}$
}

\section{INTRODUCTION}

Post mortem artefact is any change caused or a feature introduced in a body after death that is likely to lead to misinterpretation of medico legally significant ante mortem findings (1). Reddy states all events that happen after death which may simulate ante mortem injuries can be grouped together under the heading of post mortem artifacts (2). These artifacts are not related to actual pathophysiological mechanism of death and often lead to misinterpretation of medico legal important ante mortem findings which may be responsible for the cause, manner and the mode of death. Artefacts are commonly observed at autopsies which present in a form of an injury, post mortem change, pathological lesion, histological finding, bio-chemical finding, histochemical finding or as an error in photography, radiography, ultrasound and other ancillary investigations.

It is important to differentiate ante mortem injuries from the postmortem artefacts, keeping in mind the different changes which take place after the death. Lack of ability to differentiate ante mortem injuries from the post mortem artefacts may lead to incorrect assessment of time since death, wrong cause of death, miscarriage of justice, and waste of time and resources due to misleading findings (3).

Objective of this paper is to highlight certain types of artefacts authors during over 5000 autopsy examinations and discuss medico-legal issues of their interpretation and differential diagnosis with reference to available literature sources.

\section{TYPES OF ARTEFACTS AND THEIR ORIGINATION}

The postmortem artefacts are highly versatile and classified according to their origin. Iatrogenic artefacts are antemortem or peri mortem in origin and caused by various medical and surgical manipulations. Some examples are haemorrhage around the injection marks appear as contusions or snake bites, abrasions on the skin in a linear pattern after removal of the medical tape, discoid bruises on upper arms due to neurological stimulation which may be misinterpreted as injuries due to physical abuse, incisions for intercostal tubes imitating stab wounds etc.

Resuscitation artefacts accounts for reckoning portion of lesions of perimortem origin usually caused by terminal therapeutic procedures of the medical staff. Some of the common resuscitation artifacts are chest contusions and rib fractures due to cardio pulmonary resuscitation, contusion of lips due to tracheal intubation, circumscribe patterned burn marks on the chest due to defibrillation, redness and edema of larynx due to intubation, haemorrhage into the myocardium due to intra-cardiac adrenalin injection. The peri mortem origin of these lesions leads to formation of vital reaction around the lesions which make it extremely difficult to distinguish from ante 
mortem mechanical injuries. Effects of heat causes multitude of artifacts that may interfere with recognition of essentially ante-mortem lesions responsible for volitional activities and death. A pugilistic attitude due to heat stiffening of skeletal muscles being long misinterpreted as appealing volition of a murder victim. Other heat related post mortem appearance include blister formation on the skin due to burning after death, heat lacerations on skin with underlying muscles, haematoma in the extradural space, fractures of the skull and long bones, presence of coagulated blood in respiratory passages, soot particles in the oral cavity and larynx etc.

Post mortem changes are responsible for vast spectrum of artifacts, commencing from blood stained discharges at nostrils, presence of coffee-brown material in the stomach due to conversion of terminal erosions by gastric hydrochloric acid, milky spots on the epicardium due to early autolytic changes, Tache-Noire due to drying of sclera, shedding and blistering of epidermis due to decomposition which may be mistaken for thermal burns, prolapsed uterus due to the pressure following collection of gases produced in the abdomen mimicking criminal abortion, autolytic rupture of gastric mucosa (gastromalasia) may be mistaken for penetrating injury, protrusion of tongue misinterpreted as a sign of pressure on the neck.

A submersion tends to the appearance of different changes on dead bodies leading to conflicting opinions even among well experienced pathologists. The distinction between the facts and the artifacts are vital in determining whether the victim was alive at the time of entering into the fluid media. The artifacts mainly caused by submersion are rather during the process of death due to drowning. The commonly observed immersion artifacts are cutis anserine or 'Goose-Flesh' appearance of the skin due to agonal contraction of erector pilae muscle, 'washer woman's hand due to wrinkling of the skin, unusual distribution of hypostasis on face and hands, sunburns of exposed surfaces of floating bodies, discharges at natural orifices, presence of sand in upper respiratory tract and at times positive Diatom tests.

Artefacts caused by animal activities are essentially post mortem and the knowledge about the biodiversity and behavioural patterns of the fauna in the particular region is very essential in recognizing and interpretation of these lesions. These lesions appear as skin abrasions, contusions, lacerations, incised wounds, stabs, firearm injuries, fractures, disfiguring and mutilation of dead bodies. Ants are observed on the body shortly after the death. The feeding actions of ants cause irregular scalloped areas of superficial skin loss or small punctate lesions on uncovered areas of the body. Usually these injuries do not associated with bleeding but sometimes a considerable bleeding can take place where removal of the skin occurs in congested parts of the body. Rats, dogs and cats destroy exposed soft tissues which have nibbled margins. The paws of large animals like crocodiles cause multiple parallel tears on soft tissues mimicking cuts. The sharp, long canines may cause injuries mimicking penetrating injuries on the soft tissues and the bones. Artefacts due to post mortem handling of the body by undertakers and mortuary attendants consist of facial abrasions due to shaving, fracture of laryngeal cartilages 
during evisceration, multiple punctures, cuts and haemorhages due to embalming procedures, ligature marks due to tying and pulling of the body etc. Injuries like abrasions and lacerations on the skin can be produced by the manipulations of the body during handling, transportation and storage.

Artefacts are not limited to gross physical lesions. They can be present in a form of histological finding in the ancillary investigations. Some of the common histopathological artifacts are autolysis of cells resembling necrosis, blood in the renal tubules mimicking acute tubular necrosis, leucocytic reaction and pavementing of white blood cells even after cessation of circulation, presence of colonies of microorganisms in internal organs mimicking infections etc. A migration of foamy macrophages into the alveolar spaces is believed to be a post mortem phenomenon.

Biochemical artifacts include post mortem redistribution and diffusion of toxic substances, high albumin content in the tissues from hypostatic areas, low sugar levels in the vitreous humor, high $\mathrm{K}^{+}$in post mortem blood, post-mortem production of alcohol and cyanide in the blood vessels etc.

\section{DISCUSSION}

In the context of Forensic Pathology an artifact can be defined as a spurious postmortem presentation which stimulates a finding which would be significant in the course of ante-mortem events (4). These artefacts may be introduced before death, at the time of death or after the death and labeled as therapeutic artifacts, agonal artifacts and post-mortem artefacts (5). Artefacts are not illusions. It is always an objective finding observed on a body due to other than path-physiological evolution of a disease process and death. The same fact which is considered to be an artifact in relation to one particular medico legal issue could be a valuable finding in relation to another medico-legal aspect of criminal investigation. For an example; the present of a patchy abrasion due to postmortem sunburns on back aspect of the body is an artifact in relation to violent mode of death and blunt force injuries, but at the same time the fact indicates that the body was left face down position on an open area during the daytime for several hours.

In contrast to livor mortis, rigor mortis, autolysis, and putrefaction that are frequently observed in daily practice, more uncommon postmortem changes that do occur occasionally and under specific intra-individual or environmental conditions may be interpreted falsely by the inexperienced pathologists. For an example the hypostasis in the muscles located in the lateral submalleolar region and the thener eminence may mimic antemortem bruises (6). Tachiea noire may be misinterpreted as subconjunctival haemorrhege. In a retrospective study of 230 autopsies requested by the coroner's office the postmortem artifacts were mistaken for traumatic lesions in 18 reviewed cases (7). Therefore the ignorance and misinterpretation of such post mortem artefacts leads to arrive wrong cause of death, wrong manner of death, under suspicion of criminal offence, a halt in the investigation of criminal death, unnecessary spending of time and effort as a result of misleading findings or even and miscarriage of justice (8).

Resuscitation and emergency care incorporated vigorous medical intervention is another aspect in Forensic Pathology 
which cause practical difficulty to differentiate ante-mortem and post-mortem injuries. It is because in most instances the resuscitation occurs around the time of death with some degree of maintenance of circulation movements which leads to extravasation, infiltration and coagulation of blood and developing vital reaction mimicking ante-mortem injuries (9). An autopsy based survey revealed that resuscitation or iatrogenic artefacts were present in $12.84 \%$ cases, with artefactual rib fractures were found in $15 \%$ cases (10). The displaced rib fractures may inflict lung contusion, anterior mediastinal and myocardial contusions and even penetrating injuries on the lungs and heart (11). Defibrillator paddles produce hyperemic oval or ring shape burns clustered over the precordium. The Gray has described a rare artefactual injury from application of defibrillator simulating human bite (12). The other rare injuries caused by the closed chest compression are liver lacerations. The pathologist should be careful in interpretation of injuries in areas of the body where resuscitation has taken place.

Heat related artefacts are well documented in the forensic literature. The key medicolegal issue of investigation of a burnt body is to determine whether the victim was alive at the time of onset of fire, and distinguish heat related artefacts from ante mortem injuries. The most important signs of vitality in burned bodies are soot deposits in the distal respiratory tract, esophagus and the stomach as well as elevated $\mathrm{CO}-\mathrm{Hb}$ values in the blood. Analysis of 88 burnt victims revealed that about $3 \%$ of the cases the question whether there was an ante-mortem heat exposure could not be answered (13). Apart from burns the external findings may include leathery consolidation and tightening of the skin and the presence of partly long splits and so-called pugilistic attitude ${ }^{10}$ which is due to shortening and heat contractions of relatively stronger flexor muscles and does not demonstrate volition by the decedent to fight back the fire immediately before death (14). When superficial injuries are distorted with severe degree of burning, it can be extremely difficult, if not impossible to distinguish facts from artefacts. But even in charred bodies internal injuries are well preserved which helps to assume the type of external injuries (15). Heat extradural hematoma and heat fractures with chipping fragments are usually observed in skulls subjected to extensive post-mortem burns. Comminuted skull fractures with burning of fractured margins are indicative of secondary burns of already fragmented head. Burnt skull bones has a grey white colour showing a fine superficial network of heat fractures on its cortical surface which may crumble even on handling (16). The heat haematoma can resemble an extra dural haemorrhege of ante-mortem origin. The usual site at the vertex or occipitut and absence of fractures crossing the grooves of the middle meningeal arteries and the chocolate brown colour honey comb appearance helps to distinguish the heat haematoma from the extra dural haemorrhage $(16,17)$. The boiled and shrunken brain is a common finding of burns. The brain may appear swallon with widening and flattening of the gyri and obliterating the sulci due to contraction of the coagulating dura against the brain (15). The shrunken dura may split with herniation of the brain matter into the extra dural space (17). Immersion artefacts present on bodies are irrespective of whether death was due to 
Immersion artefacts present on bodies are irrespective of whether death was due to drowning or the person was dead on entering the water. Therefore, immersion artifacts do not contribute to the proof of death by drowning (18). Human body, once retained under the fluid media is subjected to many physical effects. These changes are varying in line with quality and temperature of the water stream. General putrefactive changes are delayed in the water which may lead to errant estimation of time since death $(15,19)$. Many investigators argue that the goose flesh appearance of skin is not a sign of ante mortem drowning but due to post mortem rigor mortis of erector-pile muscle of hair bulb. The presence of sand in upper trachea of a drowning victim is another point of non-consensus. An appearance of washer woman's hands is agreeable post mortem phenomenon due to prolonged immersion probably caused by post mortem vaso constriction (20). The important vital features of ante-mortem injuries could be washed off by effect of water, promoting post mortem outlook.

There is no unanimous opinion about the presence of diatoms in bone marrow as a confirmatory evidence of drowning, and the positive diatom test needs to be carefully evaluated on case by case basis $(21,22)$. Furthermore, diatoms can be present when people dye due to other nondrowning causes of death (23). The macroscopical and microscopical signs in the fresh drowned victim are non-specific and moreover putrefaction will varnish these autopsy findings quite rapidly (24). Finally what influences the decision making in favour or against the death due to drowning is neither autopsy nor diatom test alone. It is a combination of thorough autopsy in light with the right information by the police together with all other ancillary investigations (25). Dead bodies are attracted by animal population soon after death, known as taphonomic processes of corpses. The impact of animal activities on corpses may result from mere post mortem skin wounds to complete distortion of the body. The diagnosis of postmortem lesions inflicted by animals generally presents no problems; however, it can be difficult when the body is in an advanced state of putrefaction (26). Ants attack the bodies in early post-mortem interval causing abrasion like lesion. Drying of post mortem ant bites can give the impression of bruises or chemical burns $(27,28)$. Sometimes there may be significant post mortem bleeding from the ant bite giving an impression of antemortem trauma. As ants attack the uncovered areas of the body, ant bites can frequently give rise to suspicion especially if located on the neck mimicking pressure on the neck. They are also occasionally misinterpreted as patterned abrasion due to the imprinted effect of a blunt or offending object (27). Decomposition and action of necropagous species like maggots of flies result in penetrating defects resembling firearm wounds (5). Otherwise, maggots could alter existing penetrating wounds destroying key features of the original lesion. Rodent attacks, especially by mice and rats inflict superficial patchy skin loss with ragged margins with no bone damage. We have observed patterned cuts like lesions are produced in attack of corpses by large monitors. These injuries are caused by pointed nail tips of the animal.

\section{PRINCIPALS OF DIFFERENTIAL DIAGNOSIS}

According to a Canadian autopsy survey, artifact misinterpretation occurred in 
WARUSHAHENNADI, J., RUWANPURA P, RP. Post mortem artefacts that mimic deliberate physical violence and ante mortem lesions- Re visited. Sri Lanka Anatomy Journal (SLAJ), 1(2): 11-17, 2017.

$7.83 \%$ cases of all requested autopsies and $35.29 \%$ in decomposed cases (29). A study conducted in Pakistan reveled that out of 780 autopsies, 229 showed postmortem artifacts which included decomposition in 78, animal and insects producing changes in 45 , injuries due to rough handling in 40 , breaking of rigor mortis and shifting of postmortem lividity during transportation in 37, iatrogenic fracture of skull during opening in 15 , fractured ribs during resuscitation after death in 8 and exhumation producing fractures of bones in 6 bodies. In fact some degree of artefactual changes is present in almost all dead bodies.

Most of the post mortem artifacts are avoidable, or at least can be minimized with the availabilities of well-equipped mortuary room with enough storage provisions, with chemical and histopathological laboratory facilities. Trained mortuary attendants and the law enforcement who are engaged in the medico legal work will avoid infliction of artefacts. Photograph of dead bodies at recovery, on arrival to the mortuary will helpful to understand and interpret the origin of different artifacts.

Systematic post mortem examination which includes detailed history from all possible sources, overall assessment of the statue of the body, scene visit, detailed study into the examination and necessary ancillary investigation findings enables the forensic pathologist to overcome the difficulties of the identification and interpretation of the artefacts and conclude the correct decision.

\section{REFERENCES}

1. Leadbeatter S, Knight B. Resuscitation artifacts. Med. Sci. Law: 1988; 28: 200-4
2. Reddy KSN, The Essentials of Forensic Medicine and Toxicology 2003:398-402.

3. Mirza FH, Makhdoom PA. Importance of correct interpretation of post mortem artifacts in medico legal autopsies. The Journal of the Pakistan Medical Association 1998, 48:49- 52.

4. Abdullah, F. Artifacts in Forensic Pathology. Hand Book of Forensic Pathology. J.B Lippincott, 1973: 235-253.

5. Rao NG. Textbook of Forensic Medicine and Toxicology $2^{\text {nd }}$ Edition. 2010: 188190.

6. Tsokos M. Postmortem changes and artifacts occurring during the early post mortem interval. $2005 . \quad$ https: link.springer.com.Chapter 10.10. 1007/ 978 - 1-59259-910-3_5. Accesed on 10.06.2017.

7. Campobasso CP, Marchetti D, Introna F, Colonna MF. Postmortem artifacts made by ants and the effect of ant activity on decompositional rates. Am J Forensic Med Pathol. 2009; 30: 84-7.

8. Pillay VV. Conflicts of Opinion in Forensic Work - Need for a Rational Outlook. J. Indian Academy For. Med. 1993; 15: 40-41.

9. Vanesis P. Interpreting Bruises at necropsy. J. Clinical Pathology 2001; 54: 348-355.

10. Bohnert M. Forensic Pathology Reviews. 2004: 3-27.

11. White, WL \& Kleber, HD. Preventing harm in the name of help: A guide for addiction professionals. Counselor. 2008: 9, 10-17.

12. Grey TC. Defibrillator injury suggesting bite mark. Am. J Forensic Med Pathol.1989; 10; 144-5.

13. Bohnert M, Werner CR, Pollak S Problems associated with the diagnosis of vitality in burned bodies. Forensic Sci Int. 2003; 135:197-8.

14. Fish TJ, Miller LS, Braswell MC. Crime scene investigation. $2^{\text {nd }}$ Edition, Anderson Publisher, Burlington. 2010: 370.

15. Dolinak D., Matshes E, Lew OL, Forensic Pathology Principles and Practice. Elsevier Academic press. USA. 2005.

16. Dimaio VJ, Dimaio D. Forensic Pathology. $2^{\text {nd }}$ Ed. CRC press. 2000.

17. Sauko P, Knight B. Knigh`s Forensic Pathology. $3^{\text {rd }}$ Ed, London: Arnold; 2004. 12-27. 
WARUSHAHENNADI, J., RUWANPURA P, RP. Post mortem artefacts that mimic deliberate physical violence and ante mortem

18. Pounder DJ. Lecture notes; Department of Forensic Medicne, University of Dundee. Available at http://www.dundee.ac.uk/ forensicmedicine/notes/water.pdf.

19. Giertsen JC. 'Drowning', Chapter 16 In: 'The pathology of trauma', Mason JK, Purdue BN (eds), $3^{\text {rd }}$ Ed, Arnold Publishing 2000, London UK.

20. Wilder SE, Chow A. Water-immersion wrinkling is due to vasoconstriction. Muscle and Nerve 2003; 27: 307-311.

21. Hendy NI. The diagnostic value of diatoms in cases of drowning. Medicine, Science and the Law. 1973; 13: 23-34.

22. Foged N. Diatoms and drowning - once more. Forensic Science International 1983; 21: 153-159.

23. Hürlimann JP, Elber FF, Niederberger $\mathrm{K}$, Wyler RD, Diatom detection in the diagnosis of death by drowning, Int. J. Legal Med. 2000; 6-14.

24. Piette MHA, De Letter EA. Drowning: still a difficult autopsy diagnosis. Forensic Science International 2006; 163: 1-9.

25. Bajpai RC. Cases of "drowning" not backed by autopsy \& diatoms test International Journal of Medical Toxicology \& Legal Medicine 2013; 16: 45-4.

26. Tsokos M , Matschke J, Gehl A, Koops E. Klaus Puschel. Skin and soft tissue artefacts due to post mortem damage caused by rodents. Forensic Science International 1999; 104: 47-57.
27. Spitz WU, Fisher RS. Medico legal Investigation of Death: Guidelines for the Applications of Pathology to Crime Investigation. Springfield IL; Charles C. Thomas: 1993.

28. Rodriguez WC. Decomposition of Buried and submerged bodies. In: Haglund WD, Sorg. MH, eds. Forensic Taphonomy: The post mortem Fate of Human Remains. Boca Raton, CRC press; 1997: 459-467.

29. Sauvageau A, Racette S. Postmortem Changes Mistaken for Traumatic Lesions. The American Journal of Forensic Medicine and Pathology 2008; 29: 145-4.

\section{CORRESPONDENCE}

Dr. Janaki Warushahennadi

Department of Forensic Medicine, University of Ruhuna, Sri Lanka.

E mail- janakiwh@gmail.com

Received: August 2017

Accepted: September 2017 